\title{
An Evaluation of Different Coatings for TiN Microelectrode Chambers used for Neonatal Cardiomyocytes
}

\author{
Ondrej Svoboda ${ }^{1}$, Josef Skopalik ${ }^{2}$, Larisa Baiazitova ${ }^{1}$, Eva Gabrielova ${ }^{3}$, Vratislav Cmiel ${ }^{1}$, \\ Ivo Provaznik ${ }^{1}$, Zdenka Fohlerova ${ }^{4,5}$, Jaromir Hubalek ${ }^{4,5}$ \\ ${ }^{1}$ Department of Biomedical Engineering, Brno University of Technology, Brno, Czech Republic \\ ${ }^{2}$ Department of Human Pharmacology and Toxicology, University of Veterinary and Pharmaceutical \\ Sciences, Brno, Czech Republic \\ ${ }^{3}$ Department of Medical Chemistry and Biochemistry, Faculty of Medicine and Dentistry, \\ Palacky University, Olomouc, Czech Republic \\ ${ }^{4}$ Central European Institute of Technology, Brno University of Technology, Brno, Czech Republic \\ ${ }^{5}$ Department of Microelectronics, Brno University of Technology, Brno, Czech Republic
}

\begin{abstract}
Neonatal myocytes are a widely used model for modern in-vitro pharmacological screening and tissue engineering of cardiac tissue. The recording of neonatal myocyte electrophysiology in real time has still not been ideally optimised, however. The aim of this study was to evaluate the impact of using different substrates in culture (MEA) chambers on the surviving and functional electrophysiological activity of the myocytes after the first five days after isolation.

Neonatal cardiomyocytes were isolated from two dayold neonatal rats and plated on $12 \times 12$ ITO microelectrode chambers (Multi-Channel Systems) and cultured for five days.

Four coating methods were used. The PDL + fibronectin treatment displayed the highest cardiomyocyte adhesion to the electrodes (20\% of total cells in chamber after seeding) and developed contractible cells during the five days of pre-cultivation with a measurable electrical response. Nevertheless, the cells adhered to all surfacetreated MEA chambers, creating typical cell morphology, but with different success rates.
\end{abstract}

\section{Introduction}

Neonatal cardiomyocytes permit the study of many of the morphological, biochemical, toxicological, and electrophysiological characteristics of heart cells and their interactions [1,2]. The recording of neonatal myocyte actions and analysis of the signals from single cells or small aggregates in real time is one of the modern methods. Microelectrode arrays (MEAs) are one of the most modern tools; these systems are based on extracellular recordings and they have many advantages over traditional methods (e.g. patch clamp, indirect recording of ion flash by fluorescence methods). On the other hand, the preparation of the recording system and interpretation of the data have still not been ideally optimised. Ineffective preparation of MEA samples can negatively affect the results from mathematical modelling of electrophysiology and future biomedical applications. The coating of the electrode array has a significant role, not only in the attachment of the cells, but also in cell signalling and the development of cardiomyocyte electrophysiology during the first few days after seeding.
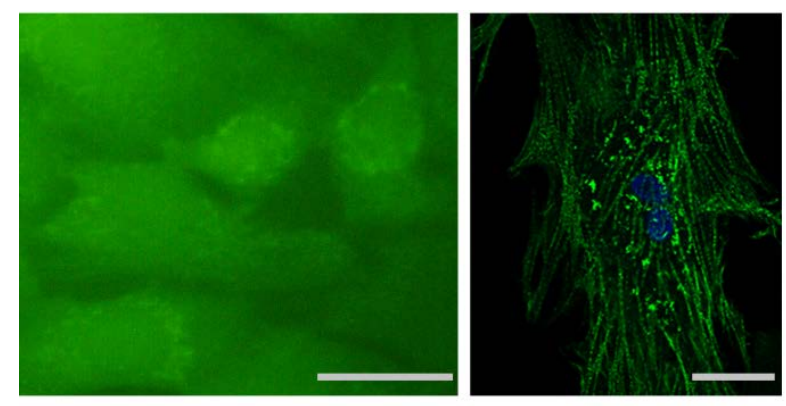

Figure 1: Typical neonatal myocytes in vitro. Left: typical geometry of cell aggregate (colour visualisation of cells using Calcein AM dye); Right: visualisation of alfa-actinin and nucleus of neonatal cardiomyocyte, day 5 after seeding. Recorded by epifluorescence microscope Olympus IX73, bar $20 \mu \mathrm{m}$.

Nowadays, there are many different MEA setups. The MEA head-stage can be wireless, which is easier to manipulate, e.g. in the cell incubator. Current MEA systems are very compact and usually have integrated temperature control, a pulse generator for sample electrical stimulation, an amplifier, and real-time signal analysis and 
feedback. Moreover, higher throughput from parallel recording is also an advantage. MEAs can also monitor action potential as well as sub-threshold responses [3,4].

Multi-electrode array chambers have many different designs, which are highly application-specific. The number of substrate-integrated recording electrodes (channels) is in the range from units to thousands in recently presented applications [5-7]. The size, shape and electrode spacing might also vary from units to hundreds of micrometres. The electrodes' active surface is usually made from $\mathrm{Au}$, Pt or TiN, which are chemically inert and easy to clean. Tracks and pads are usually made from transparent polymer, in which indium tin oxide (ITO) is used [8]. The cells are seeded on the surface of the pads, which is covered by a $50 \mu \mathrm{m}$-high (approx.) layer of coating substrate (collagen, PLL etc). Electrodes do not have direct contact with cells and they are usually several $\mu \mathrm{m}$ above the electrode surface.

\section{Material and methods}

\subsection{Preparation of cells}

Cardiomyocytes were isolated from two day-old neonatal rats by trypsin digestion $(0.2 \% \mathrm{w} / \mathrm{v})$, after which the cells were re-suspended in a medium containing Iscove's modified Dulbecco's medium (IMDM) (SigmaAldrich, I6529) and Medium 199 (Sigma-Aldrich, M4530) in a 4:1 ratio and supplemented with horse serum (10\%), fetal calf serum (5\%), penicillin $(100 \mathrm{U} / \mathrm{mL})$, and streptomycin $(100 \mu \mathrm{g} / \mathrm{mL})$. The cells were plated for $1.5-2$ hours to allow attachment and/or separation of nonmyocardial cells (heart fibroblasts). The non-adhesive cells (cardiomyocytes) were transferred into a centrifugation tube, washed, then centrifuged at $150 \times g$ for $10 \mathrm{~min}$. Suspension enriched in non-adhesive CMs was transferred to coated MEA chambers with different substrates (density $4 \times 10^{6} \mathrm{cells} / \mathrm{cm}^{2}$ ). The culture medium consisted of DMEM and medium 199 (4:1) with penicillin $\left(100 \mathrm{U} \times \mathrm{ml}^{-1}\right)$. Cultures were incubated in conditions of $21 \% \mathrm{O}_{2}$ and $5 \%$ $\mathrm{CO}_{2}$ at $37^{\circ} \mathrm{C}$. The cultivation medium was removed after 72 hours. The cell electrophysiology was studied after 120 hours from seeding.

\subsection{Multielectrode chamber coating}

Two different 120-electrode chamber designs (Multi Channel Systems) were tested $(12 \times 12$ electrode layout, 4 reference and 4 ground electrodes): i) $30 \mu \mathrm{m}$ electrode diameter with $100 \mu \mathrm{m}$ electrode spacing and ii) 30/10 $\mu \mathrm{m}$ variation. The electrodes were made from TiN (max 2\% $\mathrm{w} / \mathrm{v}$ of $\mathrm{N}$ ) and the tracks and contact pads from ITO, covered with $\mathrm{SiN}$ isolator. Chambers were cleaned with Terg-A-Zyme (Sigma-Aldrich, Z273287) and sterilised with 70\% ethanol and UV light before use.

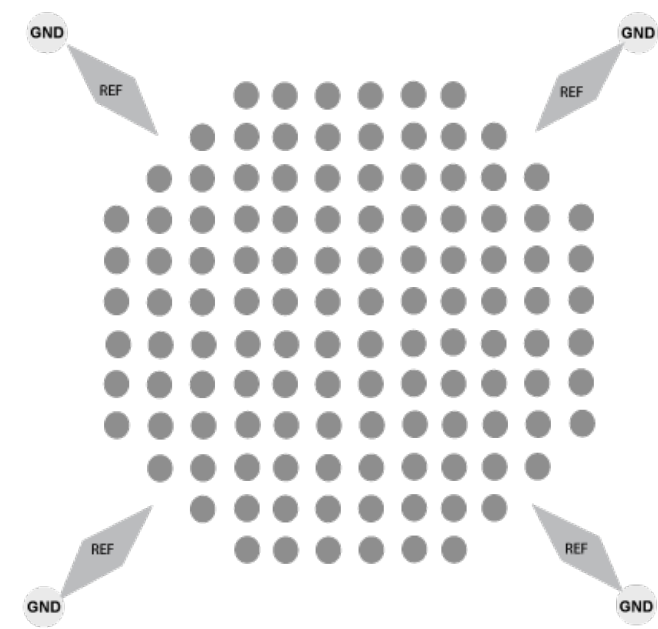

Figure 2: 120 MEA chamber layout (Multi-Channel Systems). Electrode spacing $100 \mu \mathrm{m}$.

MEA chambers were treated in four ways: i) collagen I (originated from rat tails); ii) $500 \mu \mathrm{l}$ of $0,01 \%$ poly-Llysine (PLL) (Sigma-Aldrich, P4707); iii) $500 \mu \mathrm{l}$ of 50 $\mu \mathrm{g} / \mathrm{ml}$ poly-D-lysine (PDL) (Sigma-Aldrich, P7886) were added to the chamber, keeping the $\mathrm{O} / \mathrm{N}$ at $4^{\circ}$. After the treatment, the chamber surface was rinsed twice with PBS and dried on a sterile lab bench with UV light on; iv) PDL coating was used as a substrate and covered with $400 \mu \mathrm{l}$ of $12.5 \mu \mathrm{g} / \mathrm{ml}$ porcine fibronectin (Sigma-Aldrich, F4759) for 1 hour at $37^{\circ} \mathrm{C}$ and $5 \% \mathrm{CO}_{2}$. After this, the surface was rinsed once with PBS and cells were plated immediately.

Cell adhesion and morphology were monitored with an Olympus IX73 microscope and Nikon D3100 camera. Calcein AM dye (Thermo Fischer Scientific, C3099) was used for cell viability staining.

\subsection{Electrical recording and analysis}

120 channels USB 2.0 MEA2100-System (MultiChannel Systems, Fig. 3) were used for electrical recording, with $25 \mathrm{kHz}$ sampling frequency and $\pm 10 \mathrm{mV}$ input range.

The MEA chamber was placed in the head-stage and signal baselines were recorded in $0.09 \%$ glucose buffer for 300 seconds, thereafter the buffer was replaced with $0.9 \%$ glucose and recorded for 300 seconds for spontaneous cell activity. After that, a biphasic electrical pulse from an integrated pulse (stimulus) generator was applied for a duration of $200 \mu$ s with different amplitudes (250, 500, 1000 and $2000 \mathrm{mV}$ ) and frequencies $(16.67,100,200$ and $333.33 \mathrm{mHz}$ ). Records were then analysed for point of shape, frequency, and amplitude (MC_Rack, MultiChannel Systems). 


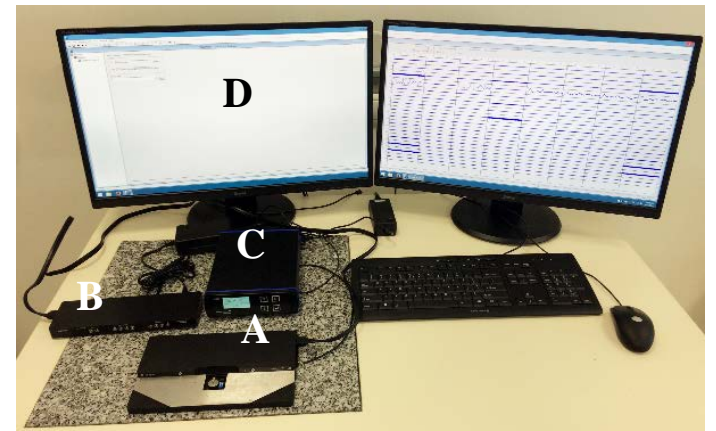

Figure 3: USB MEA2100 System measurement setup. A) Chamber holder with integrated amplifier and pulse generator. B) Interface board. C) Temperature control. D) MC Rack software with real-time signal visualisation and analysis.

\section{Results and discussion}

The neonatal cardiomyocyte display adhered to all of the coated surfaces in the MEA chamber, creating a typical cell shape (Fig. 4), but the ratio of adhered to non-adhered cells was different depending on the coating.

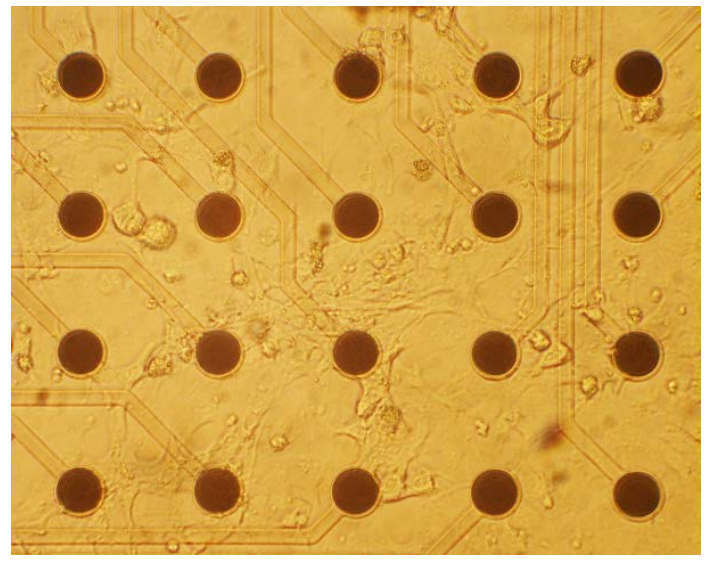

Figure 4: Neonatal cardiac cells cultured for five days on PDL+fibronectin 30/100 $\mu \mathrm{m}$ MEA chamber

The PDL+fibronectin surface treatment displayed the highest levels of cardiomyocyte adhesion to the electrode surface ( $20 \%$ of cells on $30 / 100 \mu \mathrm{m}$ chamber, as shown in Fig. 4; $18 \%$ on $10 / 30 \mu \mathrm{m}$ chamber respectively) after five days of pre-cultivation. Pure PDL also provided good cell adhesion (about 15\%). Collagen I and PLL displayed the weakest interactions with the surface, showing very low cell adhesion (0.5 5\%).

The viability of the adhered cells after five days was $>95 \%$ (Calcein AM method, illustrated in Fig. 1). The pulse stimuli were always delivered through the neighbouring electrode to the electrode with the adhered cells. The developing of functional contractive structures in the first few days after seeding was proved by alfaactinin staining (Fig. 1 - right window) and also by visual detection of rhythmical spontaneous pulsing of some cells. No spontaneous electrical activity was detected during records analysis, however; only evoked potentials were identified.

Table 1: 30/100 $\mu \mathrm{m}$ chamber neonatal cardiomyocytes adhesion

\begin{tabular}{llll}
\hline $\begin{array}{l}\text { Surface } \\
\text { treatment }\end{array}$ & $\begin{array}{l}\text { Mean } \\
\text { adhesion }\end{array}$ & $\begin{array}{l}\text { Evoked } \\
\text { response }\end{array}$ & $\begin{array}{l}\text { Desensiti- } \\
\text { sation }\end{array}$ \\
\hline Collagen I & $5 \%$ & No & No \\
PLL & $1 \%$ & No & No \\
PDL & $16 \%$ & Yes & No \\
PDL+fibronectin & $20 \%$ & Yes & Yes \\
\hline
\end{tabular}

PDL+fibronectin surface treatment on 30/100 $\mu \mathrm{m}$ chamber enabled the development of contractible cells which were electrically deactivated (desensitized) with $\geq$ $500 \mathrm{mV}$ pulses at $16.67 \mathrm{mHz}$ frequency and recovered after 10 minutes in $0.9 \%$ glucose buffer.

Table 2: 10/30 $\mu \mathrm{m}$ chamber neonatal cardiomyocyte adhesion

\begin{tabular}{llll}
\hline $\begin{array}{l}\text { Surface } \\
\text { treatment }\end{array}$ & $\begin{array}{l}\text { Mean } \\
\text { adhesion }\end{array}$ & $\begin{array}{l}\text { Evoked } \\
\text { response }\end{array}$ & $\begin{array}{l}\text { Desensiti- } \\
\text { sation }\end{array}$ \\
\hline Collagen I & $3 \%$ & No & No \\
PLL & $0.5 \%$ & No & No \\
PDL & $15 \%$ & Yes & No \\
PDL+fibronectin & $18 \%$ & Yes & No \\
\hline
\end{tabular}

Only the PDL+fibronectin and PDL samples allowed the creation of a measurable cell response. The PDL-only samples were lower in amplitude than those combined with fibronectin. Collagen I and PLL displayed very low cell adhesion $(0.5 \sim 5 \%)$ with no visible response. We therefore hypothesise that the main reason could be the low stability of both the collagen and PLL layers on our chamber's bottom surface.

The amplitude of cell response to single external stimuli from 30/100 $\mu \mathrm{m}$ MEA chamber was $198 \pm 18 \mathrm{mV}$ in the case of the PDL+fibronectin sample and $179 \pm 12 \mathrm{mV}$ in case of pure PDL. Because the MEA chamber was not fully covered with cells, the evoked cell response could not be detected on all channels.

In this study, the 30/100 $\mu \mathrm{m}$ MEA chamber with PDL+fibronectin coating was the most convenient. 


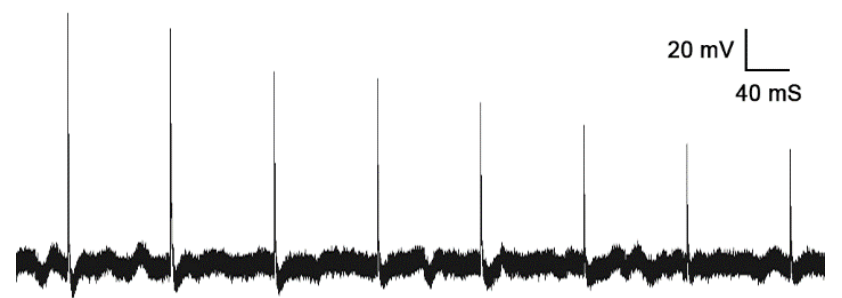

Figure 5: Cell desensitization (500 mV, $16 \mathrm{mHz}$ external stimuli)

The response amplitude from the 10/30 $\mu \mathrm{m}$ chamber was always lower (15 20\%) than in 30/100 $\mu \mathrm{m}$ one. This was due to the smaller active electrode area and higher input resistance of the $10 / 30 \mu \mathrm{m}$ chamber. In these samples, we did identify that one cell adhered to more than one electrode (2-4) several times. In these cases, the same response could be detected on parallel channels with different amplitudes (due to the different quality of cell adhesion). Unfortunately, time variances caused by different longitudinal and transverse cell membrane depolarisation conductivity could not be identified due to the low sampling frequency.

Our results reveal the importance of carefully selecting the culture substrate for cardiomyocyte adhesion, survival, and physiology. In future, simple coatings of collagen I, PDL, PDL + fibronectin and PLL should be tested over a longer time period after cardiomyocyte seeding. We also wish to investigate another modern coating based on naturally occurring complete extracellular matrix (a sophisticated mix of collagen and other components, which mimics the actual extracellular matrix in the heart).

\section{Acknowledgements}

The research described in this paper was financed by Czech Ministry of Education through the National Sustainability Program under grant LO1401 and LO1304. For research, the infrastructure of the SIX Centre was used. This work was supported by the projects of the Grant Agency GAČR P102/12/2034. The article was supported by project no. FEKT-S-14-2300, investigating new types of electronic circuits and sensors for specific applications.

\section{References}

[1] GABRIELOVA E, et. al. Silymarin component 2,3dehydrosilybin attenuates cardiomyocyte damage following hypoxia/reoxygenation by limiting oxidative stress. Physiological Research, 2015, 64.1: 79.

[2] SKOPALIK J, et. al. Formation of Cell-To-Cell Connection between Bone Marrow Cells and Isolated Rat Cardiomyocytes in a Cocultivation Model. Journal of Cell Science \& Therapy, 2014, 2014.

[3] SPIRA ME and HAI A. Multi-electrode array technologies for neuroscience and cardiology. Nature Nanotechnology 2013;8:83 - 94.

[4] PLENZ D, et. al. Multi-electrode Array Recordings of Neuronal Avalanches in Organotypic Cultures. J Vis Exp 2011;54:2949.

[5] HUYS R, et. al. Single-cell recording and stimulation with a 16k micro-nail electrode array integrated on a $0.18 \mu \mathrm{m}$ CMOS chip. Lab Chip 2012;12:1274-1280.

[6] MACCIONE A, et. al. Sensing and actuating electrophysiological activity on brain tissue and neuronal cultures with a high-density CMOS-MEA. 2013 Transducers \& Eurosensors XXVII: The 17th International Conference on Solid-State Sensors, Actuators and Microsystems 2013;752-755.

[7] BALLINI M, et. al. A 1024-Channel CMOS Microelectrode Array With 26,400 Electrodes for Recording and Stimulation of Electrogenic Cells In Vitro. IEEE Journal of Solid-State Circuits 2014;49:2705-2719.

[8] OBIEN MEJ, et. al. Revealing neuronal function through microelectrode array recordings. Front. Neurosci 2015;8:423.

Address for correspondence.

Ondrej Svoboda

Department of Biomedical Engineering

The Faculty of Electrical Engineering and Communication

Brno University of Technology

Technicka 3082/12

61600 Brno

Czech Republic

xsvobo32@stud.feec.vutbr.cz 